\title{
The current practice of using angiotensin-converting enzyme inhibitors and angiotensin II receptor blockers in diabetic hypertensive and non-hypertensive patients
}

\author{
Is there a room for vitamin $D$ ?
}

Hatouf H. Sukkarieh, PhD, Rami T. Bustami, PhD, Manasik N. Abdu, MBBS,

Ayesha A. Khokhar, HSDG, Amir A. Salih, MD, Hana K. Abdalla, PhD.

\begin{abstract}
الأهداف : إن اعتلال الكلية السكري (DN) و إن السبب الأكثر شيوعاً للمرحلة

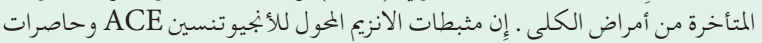

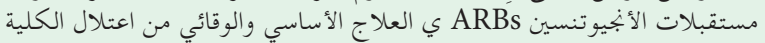

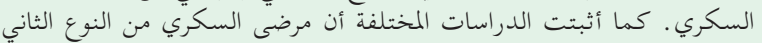

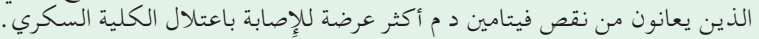

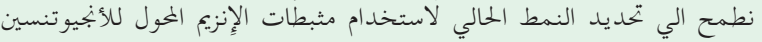

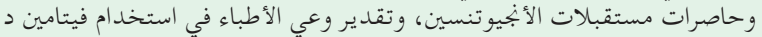

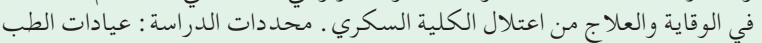

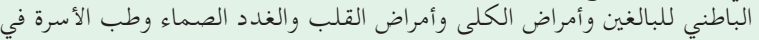
ثلاثة مستشفيات

المنهجية : قمنا بتوزيع استبيان مصدق عليه في الفترة بين أبريل 2019 إِلى نوفمبر إلماء

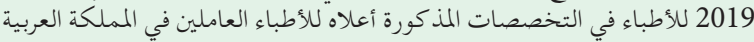

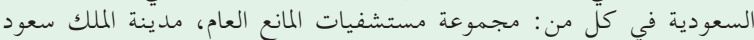

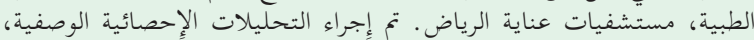

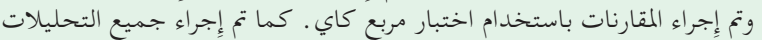

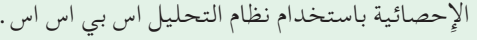

النتائج: أفاد واحد وأربعون طبيبًا باستخدام العلاج المركب لمثبطات الإتبات الإنزيم

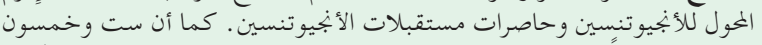

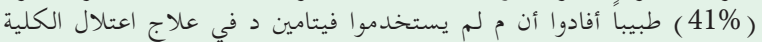

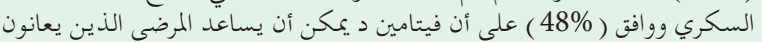

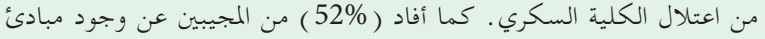

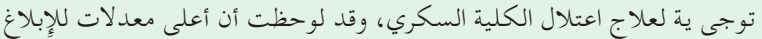

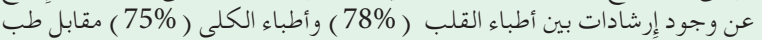

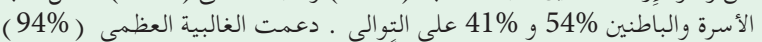

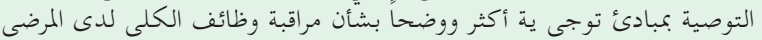

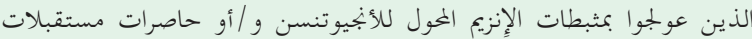

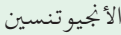

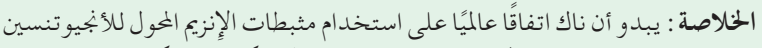

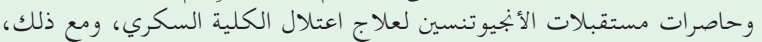

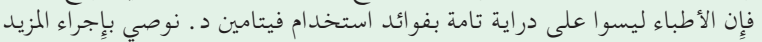

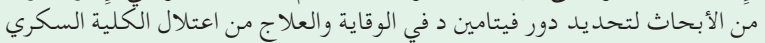

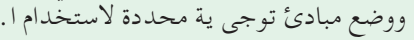

Objectives: To determine the current pattern of using angiotensin-converting enzyme (ACE) inhibitors and angiotensin II receptor blockers (ARBs) in diabetic nephropathy (DN), and assess physician awareness of using vitamin $\mathrm{D}$ in the prevention and treatment of DN.
Methods: A cross-sectional study implementing a validated questionnaire, which was distributed to physicians in the aforementioned specialties in 3 hospitals in Saudi Arabia (Almanee Hospital, King Saud Medical City [KSMC], and Riyadh Care Hospital [RCH]) between April 2019 and November 2019. We used IBM SPSS 26.0 to perform descriptive statistical analyses and comparisons were based on the Chi-square test.

Results: Forty-one physicians (30\%) reported the use of combination therapy of ACEi and ARBs. Fifty-six (41\%) physicians reported that they never used vitamin $D$ in the treatment of $\mathrm{DN}$, and $48 \%$ agreed that vitamin $\mathrm{D}$ can benefit patients with DN. $52 \%$ of the respondents reported the existence of guidelines. The vast majority (94\%) recommended clearer guidelines on monitoring renal function in patients treated with ACEi or ARBs.

Conclusion: There is a universal agreement among physicians regarding the use of $\mathrm{ACEi}$ and $\mathrm{ARBs}$ for the treatment of DN with limited awareness of the benefits of using vitamin D. Hence, the development of specific guidelines for its use are recommended.

Keywords: hypertension, clinical management, ACE inhibitors and ARBs, primary care, Vitamin D, diabetic nephropathy (DN)

Saudi Med J 2020; Vol. 41 (10): 1083-1089 doi: 10.15537/smj.2020.10.25428

From the Department of Pharmacology (Sukkarieh), from the Department of Operations \& Project Management (Bustami), from the College of Medicine (Abdu, Khokhar), from the Department of Microbiology and Immunology (Abdalla), Alfaisal University, Rivadh; and from the from the Department of Internal Medicine (Salih), Almana General Hospital, Dammam, Kingdom of Saudi Arabia.

Received 27th July 2020. Accepted 16th September 2020.

Address correspondence and reprint request to: Dr. Hatouf H. Sukkarieh, Department of Pharmacology, College of Medicine, Alfaisal University, Riyadh, Kingdom of Saudi Arabia. E-mail: hsukkarieh@alfaisal.edu ORCID ID: https://orcid.org/0000-0003-3736-5989 
Clobal burden of diabetes mellitus (DM) is Irelentlessly increasing. Diabetic nephropathy (DN), a leading cause of end-stage renal disease worldwide, is also a major cause of morbidity and mortality in patients with DM. Approximately 30-40\% of patients with diabetes develop nephropathy with renal damage, which progresses in approximately one third of patients. ${ }^{1}$ Diabetic nephropathy is defined by symptoms including proteinuria $>300 \mathrm{mg} / 24$ hours, increased blood pressure, and progressive decline in renal function and eventually culminates in end-stage renal failure requiring dialysis or transplantation in advanced cases. Early stages of the disease include microalbuminuria, in which urine incorporates minuscule quantities of protein. ${ }^{2}$ Angiotensin-converting enzyme (ACE) inhibitors and angiotensin II receptor blockers (ARBs) have been shown to decrease renal disease progression in patients with DN. ${ }^{3}$ Lisinopril is the mostly widely used ACE inhibitor for patients with DN. ${ }^{4}$ Although ACE inhibitors are generally well-tolerated, some adverse effects may include dry cough, angioedema, hyperkalemia, and extreme hypotension after the first dose. Patients who develop such adverse reactions may be switched to ARBs. ${ }^{3}$ Angiotensin II receptor blockerss, which have similar pharmacological effects as ACE inhibitors, share indications for use including heart failure, hypertension, and post-myocardial infarction but they do not cause accumulation of bradykinin which is responsible for dry cough and angioedema in ACE inhibitors. They are, however, extremely expensive ${ }^{5}$ and can cause hyperkalemia and orthostatic hypertension, just like ACE inhibitors.

The current treatment guidelines endorse the use of ACE inhibitors or ARBs for the control of blood pressure in patients with kidney disease. However, combination therapy with $\mathrm{ACE}$ inhibitors and $\mathrm{ARBs}$ is contraindicated, as it does not offer any additional clinical benefit, known for higher rates of renal impairment and may increase the risk of hyperkalemia. ${ }^{6-9}$ It is recommended by European Society of Cardiology to monitor creatinine and potassium in patients on ACEI/ ARB. ${ }^{10}$ Correspondingly, previous studies showed that $1 / 10$ th of patients initiating ACEI/ARB therapy receive the guideline-recommended creatine monitoring. Many of the patients fulfilling post-initiation termination criteria for potassium and creatinine increase continue

Disclosure. Authors have no conflict of interests, and the work was not supported or funded by any drug company. with their treatment. To reduce type 2 diabetes mellitus (T2DM) complications, early detection of nephropathy is crucial. ${ }^{11}$ Data show that DM can be controlled via increasing the amount of vitamin $\mathrm{D}$ supplemented to the body, as vitamin D is involved in the function and secretion of insulin. Studies have shown that patients with T2DM and co-existing vitamin D deficiency are at a higher risk of cardiovascular diseases and nephropathy. ${ }^{12}$ Another study showed that patients with chronic kidney disease and T2DM have a worse prognosis with comorbid vitamin $\mathrm{D}$ deficiency. ${ }^{13}$ Moreover, low vitamin D levels are associated with the development of DM and its complications. ${ }^{14}$ Prevalence of albuminuria has been shown to be higher in patients with lower levels of vitamin D. ${ }^{15,16}$

Therefore, the aims of this study were i) to determine the current pattern of using ACE inhibitors and ARBs in diabetic non-hypertensive and hypertensive patients, ii) to measure the proportion of physicians who regularly monitor renal function before and after initiation of ACE inhibitors and ARBs, iii) to assess the level of physician awareness and perception toward using vitamin $\mathrm{D}$ supplements in the prevention and treatment of $\mathrm{DN}$, and iv) to determine whether physicians include vitamin $\mathrm{D}$ in the treatment regimen for $\mathrm{DN}$.

Methods. A cross-sectional study implementing a questionnaire in English that had been adopted from a study investigating the use of ACE inhibitors and ARBs in hypertensive and non-hypertensive patients with diabetes. The widely used questionnaire has been shown to have validity and reliability. The questionnaire was administered between April 2019 and November 2019 to physicians in 3 hospitals in Saudi Arabia (Almanee Hospital, King Saud Medical City [KSMC], and Riyadh Care Hospital $[\mathrm{RCH}])$. The population included in the study was all of the 180 physicians that work in these 3 hospitals under the specialty of interests $(n=150$, $83 \%)$. Using the questionnaire, we collected extended information on existing practices for the use of ACE inhibitors and $\mathrm{ARBs}$, vitamin $\mathrm{D}$, and perceptions of physicians toward their use for patients with diabetes. The questionnaire consisted of 16 items, subdivided into 2 sections: demographic information (7 items) including age, gender, education level, profession, degree obtained, years of practice, and current practices regarding $\mathrm{ACE}$ inhibitor, $\mathrm{ARB}$, and vitamin $\mathrm{D}$ use $(9$ items). The modified questionnaire has an established validity and reliability. The study was approved by the Institutional Review Board (IRB) Committee of Alfaisal University and also by the corresponding hospitals before distributing the questionnaires. 
Physicians in the 3 hospitals were provided with an explanation of the study goals and solicited to participate. They were also given a copy of the questionnaire and were given sufficient time to fill it out. The completed questionnaires were collected and securely kept. Data were electronically saved into a suitably designed Excel database. According to the procedures for raw data management, the data was handled to identify any errors or missing information before applying the analyses. The responses were verified and subsequently matched with all possible range values for each variable with questionable values being marked. Demographic variables were also checked to detect any inaccuracies by performing frequency analyses.

Descriptive statistical analyses were carried out for participants' data. Variables were analyzed using frequencies and percentages. Use of ACE inhibitors, ARBs, and vitamin D was assessed overall, and demographic factors were analyzed using the Chi-square test. Scores measuring perceptions toward the use of these treatments were studied, analyzed and also compared by age, gender, profession, educational level, and years of practice. All comparisons were based on the Chi-square test. The allocated statistical significance was at $p<0.05$. IBM SPSS 26.0 was used to perform descriptive statistical analyses. Windows version 26.0 (IBM Corp., N.Y., USA, Armonk).

Results. A total of 138 of 150 physicians completed the questionnaire for a response rate of $92 \%$. The content validity of the questionnaire items measuring current practices and use of ACE inhibitors and ARBs was confirmed by 2 specialists who assessed the relevance of the content after making required adjustments to items to confirm they were complete, and correctly evaluated and quantified attitudes. Furthermore, the reliability of the questionnaire was scrutinized using Cronbach's alpha $(\alpha)$, which is a measure used to assess the reliability, or internal consistency, of a set of scale or test items. The Cronbach's $\alpha$ value was 0.68 , reflecting an adequate degree of internal consistency.

The vast majority of participants were $\geq 30$-year-old $(83 \%)$, and $71 \%$ were males (Table 1$)$. The distribution of profession was as follows: $41 \%$ Doctor (MD), 22.5\% Master, 14.5\% Bachelor, 10.9\% Diploma and 9.4\% PhD. Approximately 60\% were nephrologists or internists, $18.8 \%$ Family Medicine, 16\% Cardiologists and $9 \%$ Endocrinologists. Most respondents attained their degree outside Saudi Arabia (76\%). The distribution of years of practice years was as follows: $19.6 \%<5$ years, $42 \% 5-15$ years and $38.4 \%>15$ years. Fifty-two percent of responses showed the presence of guidelines for the treatment of hypertensive and non-hypertensive diabetic patients (Table 2). Only 65 of the 138 respondents (47\%) stated that they have a preferable medication for the treatment of hypertensive/ non-hypertensive diabetic patients. Forty-one percent of respondents reported that they never used vitamin D in treating diabetic nephropathy and approximately $48 \%$ thought that vitamin D can help patients with diabetic nephropathy. The vast majority (94\%) reported that renal function should be monitored after the start of treatment of ACE inhibitors and ARBs, and the same

Table 1 - Study sample descriptive statistics (N=138).

\begin{tabular}{|c|c|}
\hline Factor & n $(\%)$ \\
\hline \multicolumn{2}{|l|}{ Hospital } \\
\hline Almena Hospital & $50(36.2)$ \\
\hline King Saud Medical City & $58(42.0)$ \\
\hline Riyadh Care Hospital & $30(21.7)$ \\
\hline \multicolumn{2}{|l|}{ Gender n (\%) } \\
\hline Female & $40(29.0)$ \\
\hline Male & $98(71.0)$ \\
\hline \multicolumn{2}{|l|}{ Age group (years) $n(\%)$} \\
\hline$<30$ & $23(16.7)$ \\
\hline $30-45$ & $44(31.9)$ \\
\hline$>45$ & $71(51.4)$ \\
\hline \multicolumn{2}{|l|}{ Education level $n(\%)$} \\
\hline Diploma & $15(10.9)$ \\
\hline Bachelor & $20(14.5)$ \\
\hline Doctor (MD) & $57(41.3)$ \\
\hline Master & $31(22.5)$ \\
\hline $\mathrm{PhD}$ & $13(9.4)$ \\
\hline Missing & $2(1.4)$ \\
\hline \multicolumn{2}{|l|}{ Profession $n(\%)$} \\
\hline Cardiologist & $18(13.0)$ \\
\hline Endocrinologist & $12(8.7)$ \\
\hline Family Medicine & $26(18.8)$ \\
\hline Internist & $74(53.6)$ \\
\hline Nephrology & $8 \quad(5.8)$ \\
\hline \multicolumn{2}{|l|}{ Degree awarded $n$ (\%) } \\
\hline Inside Saudi Arabia & $32(23.2)$ \\
\hline Outside Saudi Arabia & $105(76.1)$ \\
\hline Missing & $1 \quad(0.7)$ \\
\hline \multicolumn{2}{|l|}{ Years of practice $n(\%)$} \\
\hline$<5$ & $27(19.6)$ \\
\hline $5-15$ & $58(42.0)$ \\
\hline$>15$ & $53(38.4)$ \\
\hline \multicolumn{2}{|c|}{ Years of practice in KSA $n$ (\%) } \\
\hline$<5$ & $33(23.9)$ \\
\hline $5-15$ & $73(52.9)$ \\
\hline$>15$ & $31(22.5)$ \\
\hline Missing & $1 \quad(0.7)$ \\
\hline
\end{tabular}


Table 2 - Existing practices of use of ACEi and/or ARBs in the study sample $(\mathrm{N}=138)$.

\begin{tabular}{|c|c|c|}
\hline Item & $\begin{array}{c}\text { No. of } \\
n\end{array}$ & $\begin{array}{l}\text { responses } \\
(\%)\end{array}$ \\
\hline \multicolumn{3}{|c|}{$\begin{array}{l}\text { Guidelines for the treatment of hypertensive/non-hypertensive diabetic } \\
\text { patients? }\end{array}$} \\
\hline Yes & 72 & $(52.2)$ \\
\hline No & 33 & (23.9) \\
\hline Not sure & 32 & $(23.2)$ \\
\hline Missing & 1 & $(0.7)$ \\
\hline \multicolumn{3}{|c|}{$\begin{array}{l}\text { Preferable medication for the treatment of hypertensive/non-hypertensive } \\
\text { diabetic patients }\end{array}$} \\
\hline ACE Inhibitors & 65 & $(47.1)$ \\
\hline ARBS & 29 & $(21.0)$ \\
\hline ACE and ARBS & 41 & $(29.7)$ \\
\hline Other & 3 & $(2.2)$ \\
\hline \multicolumn{3}{|c|}{ Vitamin D use in treatment of $D N$} \\
\hline Frequently & 20 & $(14.5)$ \\
\hline Occasionally & 33 & $(23.9)$ \\
\hline Rarely & 29 & $(21.0)$ \\
\hline Never & 56 & $(40.6)$ \\
\hline \multicolumn{3}{|c|}{ Common practice to determine RFT before starting ACE/ARB? } \\
\hline Yes & 105 & $(76.1)$ \\
\hline No & 13 & $(9.4)$ \\
\hline Not sure & 18 & $(13.0)$ \\
\hline \multicolumn{3}{|c|}{ Vitamin D can help patients with DN } \\
\hline Strongly agree & 11 & $(8.0)$ \\
\hline Agree & 55 & (39.9) \\
\hline Neutral & 39 & $(28.3)$ \\
\hline Disagree & 12 & $(8.7)$ \\
\hline Strongly disagree & 0 & $(0.0)$ \\
\hline \multicolumn{3}{|c|}{$\begin{array}{l}\text { Renal function should be monitored after the start of treatment of } A C E \\
\text { inhibitors/ARBs }\end{array}$} \\
\hline Strongly agree & 74 & $(53.6)$ \\
\hline Agree & 56 & $(40.6)$ \\
\hline Neutral & 6 & $(4.3)$ \\
\hline Disagree & 1 & $(0.7)$ \\
\hline Strongly disagree & 1 & $(0.7)$ \\
\hline \multicolumn{3}{|c|}{ Deterioration of renal function is an indication to discontinue $A C E / A R B s$} \\
\hline Strongly agree & 27 & $(19.6)$ \\
\hline Agree & 56 & $(40.6)$ \\
\hline Neutral & 23 & $(16.7)$ \\
\hline Disagree & 11 & $(8.0)$ \\
\hline Strongly disagree & 1 & $(0.7)$ \\
\hline \multicolumn{3}{|c|}{$\begin{array}{l}\text { I support the recommendation of clearer guidelines on the monitoring of } \\
\text { renal function in patients treated with ACEi and/or ARBs. }\end{array}$} \\
\hline Strongly agree & 71 & $(51.4)$ \\
\hline Agree & 59 & $(42.8)$ \\
\hline Neutral & 6 & $(4.3)$ \\
\hline Disagree & 0 & $(0.0)$ \\
\hline Strongly disagree & 0 & $(0.0)$ \\
\hline
\end{tabular}

percent of respondents support the recommendation of clearer guidelines on the monitoring of renal function in patients treated with ACE inhibitors and/or ARBs.

Table 3 shows survey results for the use of ACEi and/or ARBs by demographic characteristics of the respondents. The rate of reporting the presence of guidelines for the treatment of hypertensive/non-hypertensive diabetic patients varied significantly by most demographics and practice-associated factors (hospital, profession and years of practice $(p<0.05)$. Substantially higher rates of reporting the presence of guidelines for the treatment of hypertensive/non-hypertensive diabetic patients were observed among cardiologists $(78 \%)$ and nephrologists $(75 \%)$ versus family medicine (54\%) and internists $(41 \%)$.

Discussion. Our study showed that $48 \%$ of questionnaire respondents were aware that vitamin $\mathrm{D}$ can confer benefits to patients with DN.

Guidelines produced by National Kidney Foundation (NKF) and the American Diabetes Association (ADA) suggest screening patients with

Table 3 - Practices of the Use of ACE Inhibitors and ARBs (N=138).

\begin{tabular}{|c|c|c|c|c|}
\hline Factor & $\mathrm{N}$ & $\mathbf{n}$ & (\%) & $P$-value* \\
\hline Hospital & & & & 0.046 \\
\hline Almena Hospital & 50 & 23 & $(46.0)$ & \\
\hline King Saud Medical City & 58 & 36 & $(62.1)$ & \\
\hline Riyadh Care Hospital & 30 & 13 & $(43.3)$ & \\
\hline Profession & & & & 0.022 \\
\hline Cardiologist & 18 & 14 & (77.8) & \\
\hline Endocrinologist & 12 & 8 & $(66.7)$ & \\
\hline Family Medicine & 26 & 14 & $(53.8)$ & \\
\hline Internist & 74 & 30 & $(40.5)$ & \\
\hline Nephrology & 8 & 6 & $(75.0)$ & \\
\hline Degree obtained & & & & 0.050 \\
\hline Inside Saudi Arabia & 32 & 15 & $(46.9)$ & \\
\hline Outside Saudi Arabia & 105 & 56 & (53.3) & \\
\hline Years of practice & & & & $<0.001$ \\
\hline$<5$ & 27 & 9 & (33.3) & \\
\hline $5-15$ & 53 & 33 & $(62.3)$ & \\
\hline$>15$ & 58 & 30 & $(51.7)$ & \\
\hline
\end{tabular}


T2DM for microalbuminuria at diagnosis, as studies have found that $7 \%$ of patients present with kidney disease at diagnosis of T2DM. The NKF recommends serum creatinine for glomerular filtration rate (GFR) estimation, as well as urine albumin excretion to be monitored annually. American Diabetes Association recommends urine albumin excretion alone and subsequent serum creatinine for estimated GFR if the urine albumin is increased beyond $30 \mathrm{mg} / \mathrm{L} .{ }^{17}$ Following positive screening for microalbuminuria, as per ADA guidelines, annual urine albumin should be checked to monitor DN and the response to therapy. ${ }^{18}$ In this multicenter cross-sectional study, the majority of respondents, ranging from medical practitioners of various specialties to master's and $\mathrm{PhD}$ holders, thought that renal function should be monitored prior to and upon initiation of ACEi and/or ARBs in patients with diabetes, which is in line with the ADA guidelines.

One important reason for testing renal function post initiation of $\mathrm{ACEi}$ or ARBs is the risk of precipitating acute kidney failure. Should a clinician pick up a 30\% increase in serum creatinine above baseline within 2 months of initiation of therapy or if serum potassium persists above $5.6 \mathrm{mEq} / \mathrm{L}$, ACE inhibitors should be discontinued. ${ }^{19}$

Almost all questionnaire respondents agreed to the indication of ACE inhibitors and/or ARBs for microalbuminuria in normotensive individuals, following the Cochrane Systematic review, which recommends the use of these drugs as a first-line option to reduce the progression of the disease. ${ }^{20}$ Almost a third of the respondents, however, admitted to the use of ACEi and ARBs simultaneously, which in a doubleblinded randomized control trial was discouraged due to increased risks without evidence of improved efficacy. ${ }^{21}$

The deficiency of vitamin D is linked to microvascular complications in patients with DM, perhaps facilitating the development of DN. ${ }^{13}$ The results of this study showed that only approximately $48 \%$ of questionnaire respondents were aware that vitamin $\mathrm{D}$ has been shown to confer benefits to patients with DN. This indicates a lack of awareness on the benefits of vitamin D and its effectiveness in DN. A systematic review and metaanalysis evaluating the role of vitamin $\mathrm{D}$ or its analogue in the management of DN showed a significant improvement of proteinuria in patients with $\mathrm{DN}$ and an overall improvement in renal function. ${ }^{22}$ A systematic review published in 2018 including 16 studies that met inclusion criteria showed that prevalence of vitamin D deficiency in Saudi Arabia (63\%) and more specifically Riyadh (31\%). ${ }^{23}$ Moreover, this study demonstrates that up to $52 \%$ of clinicians have not been incorporating vitamin $\mathrm{D}$ to their plan of care in a high risk population.

In this study, $41 \%$ of questionnaire respondents reported never using vitamin $\mathrm{D}$ in the treatment of $\mathrm{DN}$, which could be partly explained by limited recommendations/guidelines. Most patients with $\mathrm{DN}$ have been receiving vitamin $\mathrm{D}$ supplements for vitamin $\mathrm{D}$ deficiency, as the 2 conditions commonly co-exist; therefore, clinicians may not consider modifying vitamin $\mathrm{D}$ regimens solely for the treatment of $\mathrm{DN}$.

The major strength of this study is its uniqueness in comparison to other studies that solely focused on improving the use of ACEis and ARBs in the gulf region before evaluating the current practice. We used an instrument that was carefully constructed to examine physician's current practice and attitude toward ACEi and ARBs. In addition, we explored the association between the demographic characteristics and workingexperience with the ongoing clinical application of ACEi and ARBs.

On the other hand, the limitations were mostly due to participants being self-enrolled in the study which may lead to poor external validity to other hospitals in the region as well as worldwide and sample bias cannot be ruled out. Also, the questionnaires were in English, which for many respondents was not their first language resulting in a potential space for false interpretation. Furthermore, as with all cross-sectional studies carried out using paper-based questionnaires, they lack nuance and there is risk of unconscientious responses. We also did not stratify the results based on speciality of responder, level of experience or to what degree of clinical involvement they had with the management of diabetic nephropathy.

In overcoming these limitations, we successfully administered the survey to $80 \%$ of the physicians in the 3 hospitals under the specialties of interest. Although we used a convenience sampling we were able to cover the vast majority with a $92 \%$ response rate. Moreover, we specifically chose to implement an instrument that consisted of a broad range of items and practices on the application of ACEi and ARBS. We aim to conduct more studies to extract additional information that reflect the reasons for these practices and opinions. Of note, Saudi Arabia has not produced guidelines for the treatment of DN thus far, further investigation into the guidelines different providers refer to for implementing evidence based medicine could be beneficial. Moreover, expanding the study to include an intervention such as a didactics to residents that are involved in the care of diabetic nephropathic patients and re-distributing the questionnaire to see if their practice has been modified. 
In conclusion, there seems to be a universal agreement regarding the use of ACE inhibitors and $A R B s$ in the treatment of patients with DN. Renal function tests were used regularly to monitor the progression of DN and response to therapy. Physicians, however, were not fully aware of the benefit of using vitamin $\mathrm{D}$ in patients with $\mathrm{DN}$. This is likely to be due to a lack of a local generating body for guidelines regarding the management of diabetic nephropathy. The literature lacks recent data on the incidence of diabetic nephropathy among the Saudi population. But, one study, showed Saudi to be one of the countries with the highest rate of T2DM and renal complications of diabetes in adult populations. "In 2011, it was estimated that $42.5 \%$ of end stage renal disease (ESRD) cases in Saudi Arabia were related to diabetes, and the cost for dialysis in this country amounts to SR173,784 (US\$46,332) per patient per year." ${ }^{24}$ This justifies the need for more research investigating the implementation of the best level of care for the adult population of diabetics.

While vitamin $\mathrm{D}$ deficiency is a common finding in patients with chronic kidney disease, there is a profound shortage of guidelines for its use in clinical practice. Thus, further research is warranted to establish the role of vitamin $\mathrm{D}$ in the prevention and treatment of $\mathrm{DN}$. In addition, we recommend the development of clear, specified, and detailed guidelines for the use of vitamin $\mathrm{D}$ in the treatment of patients with DN that is tailored to a population that at least shares the characteristics of Saudi Arabia including but not limited to high deficiency of vitamin D and DN prevalence.

In conclusion, the burden of disease of diabetic nephropathy as well as -min D deficiency in Saudi Arabia is high. There is evidence for the benefits of supplementing diabetes complicated by nephropathy with vitamin $\mathrm{D}$. Additionally, there is evidence for the no added benefit, but on the contrary added risk of using both ACEi and ARBs simultaneously. This study displayed the need for clearer guidelines for management of diabetes complicated by nephropathy.

Acknowledgment. The authors acknowledge
Hamna Abdul Muthalib and Jude Alshamrani. We would like to thank
Editage (www.editage.com) for English language editing.

\section{References}

1. Tesch GH. Diabetic nephropathy - is this an immune disorder? Clinical Science 2017; 131: 2183-2199.

2. Donnelly R. ABC of arterial and venous disease: Vascular complications of diabetes. BMJ 2000; 320: 1062-1066.
3. Vivian EM, Rubinstein GB. Pharmacologic management of diabetic nephropathy. Clinical Therapeutics 2002; 24: 1741-1756.

4. Amann B, Tinzmann R, Angelkort B. ACE Inhibitors Improve Diabetic Nephropathy Through Suppression of Renal MCP-1. Diabetes Care 2003; 26: 2421-2425.

5. Park C, Wang G, Ng BP, Fang J, Durthaler JM, Ayala C. The uses and expenses of antihypertensive medications among hypertensive adults. Research in Social and Administrative Pharmacy 2020; 16: 183-189.

6. Hsu FY, Lin FJ, Ou HT, Huang SH, Wang CC. Renoprotective Effect of angiotensin-converting enzyme inhibitors and angiotensin II receptor blockers in diabetic patients with proteinuria. Kidney Blood Press Res 2017; 42: 358-368.

7. Herman WH. Response to Comment on American Diabetes Association. Approaches to Glycemic Treatment. Sec. 7. InStandards of Medical Care in Diabetes-2015. Diabetes Care 2015; 38 (Suppl. 1): S41-S48.

8. Fried LF, Emanuele N, Zhang JH, Brophy M, Conner TA, Duckworth W, et al. Combined Angiotensin Inhibition for the Treatment of Diabetic Nephropathy. New England Journal of Medicine 2013; 369: 1892-1903.

9. Juarez GF, Luño J, Barrio V, Vinuesa SGD, Praga M, Goicoechea $\mathrm{M}$, et al. Effect of dual blockade of the renin-angiotensin system on the progression of type 2 diabetic nephropathy: A randomized trial. Am J Kidney Dis 2013; 61: 211-218.

10. Ponikowski P, Voors AA, Anker SD, Bueno H, Cleland JG, Coats AJ, et al. 2016 ESC Guidelines for the diagnosis and treatment of acute and chronic heart failure: The Task Force for the diagnosis and treatment of acute and chronic heart failure of the European Society of Cardiology (ESC) Developed with the special contribution of the Heart Failure Association (HFA) of the ESC. European Heart Journal 2016; 37: 2129-2200.

11. Schmidt M, Mansfield KE, Bhaskaran K, Nitsch D, Sørensen HT, Smeeth L, Tomlinson LA. Adherence to guidelines for creatinine and potassium monitoring and discontinuation following renin-angiotensin system blockade: a UK general practice-based cohort study. BMJ Open 2017; 7: e012818.

12. Aljack H, Abdalla M, Idris O, Ismail A. Vitamin D deficiency increases risk of nephropathy and cardiovascular diseases in Type 2 diabetes mellitus patients. Journal of Research in Medical Sciences 2019; 24: 47.

13. Usluogullari CA, Balkan F, Caner S, Ucler R, Kaya C, Ersoy $\mathrm{R}$, et al. The relationship between microvascular complications and vitamin $\mathrm{D}$ deficiency in type 2 diabetes mellitus. $B M C$ Endocrine Disorders 2015; 15: (1).

14. Senyigit A. The association between 25-hydroxy vitamin D deficiency and diabetic complications in patients with type 2 diabetes mellitus. Diabetes \& Metabolic Syndrome: Clinical Research \& Reviews 2019; 13: 1381-1386.

15. Tiryaki Ö, Usalan C, Sayiner ZA. Vitamin D receptor activation with calcitriol for reducing urinary angiotensinogen in patients with type 2 diabetic chronic kidney disease. Renal Failure 2015; 38: 222-227.

16. Peng Y, Li LJ. Serum 25-hydroxyvitamin D level and diabetic nephropathy in patients with type 2 diabetes mellitus. International Urology and Nephrology 2015; 47: 983-989.

17. National Kidney Foundation. K/DOQI clinical practice guidelines for chronic kidney disease: evaluation, classification and stratification. Am J Kidney Dis 2002; 39 (Suppl 1): S46-S64. 
18. American Diabetes Association. Executive Summary: Standards of Medical Care in Diabetes-2011. Diabetes Care 2011; 34 (Supplement 1): S4-S10.

19. Bakris GL, Weir MR. Angiotensin-Converting Enzyme Inhibitor-Associated Elevations in Serum Creatinine. Archives of Internal Medicine 2000; 160: (5).

20. Lv J, Perkovic V, Foote CV, Craig ME, Craig JC, Strippoli GF. Antihypertensive agents for preventing diabetic kidney disease. Cochrane Database Syst Rev

. 2012; 12: CD004136.

21. Mann JF, Schmieder RE, Mcqueen M, Dyal L, Schumacher H, Pogue J, et al. Renal outcomes with telmisartan, ramipril, or both, in people at high vascular risk (the ONTARGET study): a multicentre, randomised, double-blind, controlled trial. The Lancet 2008; 372: 547-553.
22. Chokhandre MK, Mahmoud MI, Hakami T, Jafer M, Inamdar AS. Vitamin D \& its analogues in type 2 diabetic nephropathy: a systematic review. Journal of Diabetes \& Metabolic Disorders 2015; 14: 58.

23. Al-Alyani H, Al-Turki HA, Al-Essa ON, Alani FM, Sadat-Ali M. Vitamin D deficiency in Saudi Arabians: a reality or simply hype: a meta-analysis (2008-2015). Journal of Family \& Community Medicine 2018; 25: 1.

24. Al-Rubeaan K, Siddiqui K, Al-Ghonaim MA, Youssef AM, AlNaqeeb D. The Saudi Diabetic Kidney Disease study (SaudiDKD): clinical characteristics and biochemical parameters. Ann Saudi Med 2018; 38: 46-56. 